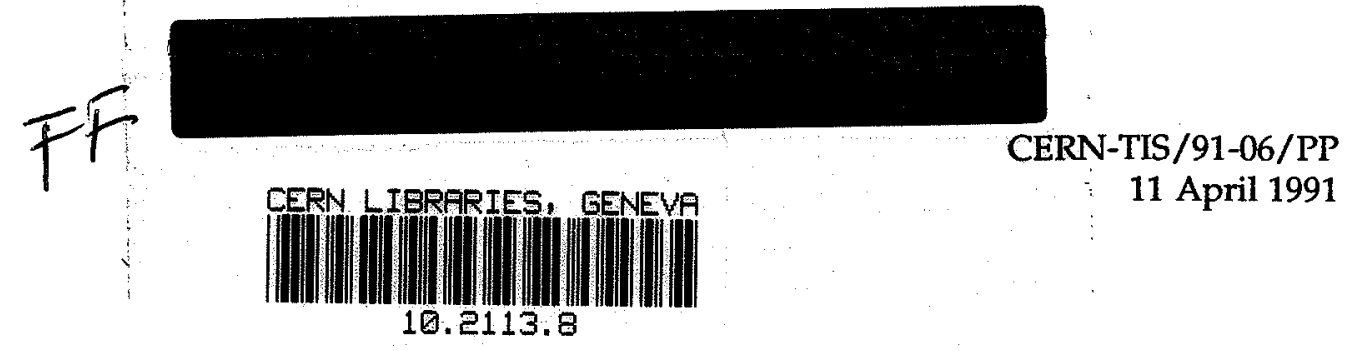

\title{
A LONG-TERM STUDY OF PERSONAL NEUTRON MONITORS IN STRAY FIELDS AROUND HIGH ENERGY-PROTON ACCELERATORS
}

\author{
M. Höfert
}

\begin{abstract}
The results are presented of a long-term study of personal neutron monitors intended to be used in stray fields around high-energy proton accelerators. The aim of this study was to investigate the possibility of using the NTA emulsion, CR39, and Makrofol (polycarbonate) as personal monitors over extended periods given the low neutron dose rates outside the biological shielding of the accelerators operated at CERN. Considering the low doses recorded, a conservative interpretation of the detector result in terms of dose equivalent is nearly always possible, thus overcoming the problems of energy response of the detectors under test. The results show that any of the track detectors can be used for the purpose of long-term monitoring, so that the final decision on the choice is based on the costs involved.
\end{abstract}

To be submitted to the Radiation Protection Dosimetry Journal 


\section{INTRODUCTION}

Neutron personal monitoring at CERN is performed at present using the NTA film sealed in an aluminized plastic pouch in dry nitrogen since it is commercially available from the National Radiological Protection Board (NRPB) in the UK(1). It has been shown, that in such a way, the nuclear emulsion is protected against fading and can be carried for periods up to three months as a personal monitor in hadron stray fields outside the main shielding of a high-energy accelerator ${ }^{(2)}$.

In the past, a study was made at CERN to see whether the NTA film could be replaced by another personal neutron monitor. As a result of the investigation it was stated that a suitable neutron dosemeter for use in the radiation environment around high-energy accelerators does not exist. On the other hand, CR39 was considered as a possible personal monitor, with the provision that a long-term supply of detectors of reproducible response and low background could be guaranteed whilst as a result of this earlier study Makrofol (polycarbonate) had been found to be too insensitive for the purposes of individual monitoring ${ }^{(3)}$.

\section{PRESENT SITUATION AND OBJECTIVES}

The radiation situation has not changed at CERN since the last study was performed. In particular, considering the low neutron dose rates encountered in experimental areas, no need for a personal neutron dosemeter has arisen since and any threshold detector fulfilling the requirements of an individual monitor on a longterm basis could be employed. In fact, most of the presently used NTA films show zero exposure, with only a few recorded doses ranging between 0.2 and $0.6 \mathrm{mSv}$ for a wearing period of two months and with a conservative interpretation of counted tracks into dose equivalent ${ }^{(4)}$.

Hence the main objective of the present study was to investigate presently available passive neutron detectors and to see whether they could be used for periods of the order of three months as personal monitors, i.e. to test these detectors in view of their long-term stability.

\section{DETECTORS AND EXPERIMENTAL CONDITIONS}

The following nuclear track detectors were included in the present study:

i) the NTA film sealed under dry nitrogen as described in the Introduction (1),

ii) CR39 described in Ref.(5) and which is now commercially available from $\operatorname{NRPB}(6)$, 
iii) Makrofol from KfK Karlsruhe treated by a new etching technique as explained in Ref.(7).

Track detectors with a threshold in the $\mathrm{MeV}$ range have been shown to be appropriate for individual monitoring in the case of broad neutron energy distributions in stray fields outside thick shields, where under equilibrium conditions the secondary particle component is determined by the high-energy particles $(8,9)$.

In Fig. 1 the energy dependence of the track detectors tested is plotted as the number of tracks per unit surface and dose equivalent $\mathrm{H}^{\prime}(10)$ as a function of energy for a perpendicular neutron incidence on the detector. The energy response for the NTA emulsion was determined at CERN whilst that of the other detectors was taken from the literature ${ }^{(5,7)}$. It is generally observed that the sensitivity of CR39 is highest around $300 \mathrm{keV}$ and starts to decrease in the $\mathrm{MeV}$ range, as has again been reported recently $(10)$. The energy dependence for the Pershore Moulding material used by NRPB is the one expected, except for the increase in sensitivity at the $14 \mathrm{MeV}$ point. As far as the energy response of polycarbonate is concerned a threshold behaviour of the detector material is obvious. Makrofol foils having first undergone a chemical followed by an electrochemical etching procedure had been used in the previous investigation with the conclusion that the sensitivity of the material was not sufficient for the purposes of personal neutron monitoring(3). However, a new method consisting of a two step electrochemical etching process has decreased the energy threshold and at the same time considerably increased the sensitivity of this material(11).

In a routine application of these detectors as individual monitors, knowing their energy response to neutron dose equivalent, one constant figure for converting tracks into dose equivalent is generally used. It is chosen such that for most of the radiation fields encountered in a given installation the conversion of the detector result into dose equivalent will be conservative. Hence, at CERN the NTA film is calibrated with neutrons from a ${ }^{238} \mathrm{Pu}$-Be source, which leads to a standard interpretation of $11 \mathrm{mSv}^{-1} \mathrm{~mm}^{-2}$. For high-energy hadron stray fields typically prevailing outside the shielding this conversion is overestimates the dose equivalent by a factor of two. The measured track-length distribution in the nuclear emulsion can be used to correct the final dose result in the case where non-trivial neutron doses are registered(12).

In this intercomparison the calibration of Makrofol had been performed with ${ }^{241} \mathrm{Am}$-Be source neutrons and leads to a conversion of $38 \mathrm{mSv}^{-1} \mathrm{~cm}^{-2}$, which should again be conservative in high-energy neutron fields. In the case of CR39, traditionally 
${ }^{252} \mathrm{Cf}$ neutrons are used for calibration. A typical figure for the transformation of tracks into dose equivalent is $40 \mathrm{mSv}^{-1} \mathrm{~cm}^{-2}$.

Nuclear track dosemeters of all three types were either carried by persons or exposed in the stray field on phantoms in specific locations, mostly outside the main shield of the CERN proton accelerators and only in some cases in radiation areas that are not accessible during accelerator operation. In fact, dose rates caused by neutrons in controlled radiation areas are generally so low that it is difficult to accumulate appreciable doses even if detectors are exposed for extended periods. The irradiations in fixed positions included generally the three types of track detectors and were performed close to installed radiation monitors during the following periods in 1989:

I: $\quad 25$ April to 30 June

II: $\quad 11$ July to 28 September

III: 23 October to 22 December

IV: $1-13$ November

$\mathrm{V}: \quad 15-27$ November

VI: November

Periods IV to VI have to be considered as sub-periods of III. The radiation monitors around CERN are in most cases high-pressure-filled argon ionization chambers, a few containing a hydrogen filling to enhance their response to neutrons. These monitors are calibrated in dose equivalent against the results of field measurements. The set of instruments used in stray fields is called Cerberus and has been described earlier(13). It is generally assumed that whilst intensities may change, the spectral conditions at the point of measurement remain constant in time.

\section{RESULTS AND DISCUSSION}

Parallel to the intercomparisons the reproducibility of the track detectors was tested with isotopic neutron sources for the three main periods mentioned above. The results are presented in Table 1. Generally two detectors were irradiated at CERN with one dose value and sent together with the detectors exposed in the stray field for an evaluation.

The NTA emulsion shows the expected stability as it has been experienced at CERN over years. Except for the second irradiation period, where one unexplained high value is indicated by a question mark, the doses deduced from the result of CR39 are higher than those they were exposed to. In the case of Makrofol the reproducibility of a batch of detectors could be tested during period II, i.e. the doses reported are mean values over three detectors each with their standard deviation. The exceptionally high readings for period III for some detectors were finally attributed to the influence of 
radon that could have penetrated into the protecting plastic pouch owing to a bad sealing. The problem of radon interacting with the detector material is known to be of particular importance when personal monitors are carried over prolonged periods.

The detectors worn by people during periods I to III showed practically only background, i.e. the same result as usually seen on the NTA film although an effort was made to choose, as far as possible, persons with a high neutron 'risk'. Therefore, only in three cases were doses ranging between 0.2 and $0.4 \mathrm{mSv}$ attributed to the wearer of a plastic detector.

The most interesting results are those in Table 2, where the integrated doses of various monitors are compared with the doses registered by the different passive detectors. Column 1 gives the number of the monitor, column 2 the number of the irradiation period, and column 3 a short description of the monitor position or the field conditions is given. The following columns contain the integrated dose rates of the monitor in $\mathrm{mSv}$, the doses recorded on the gamma film, and finally the neutron doses registered on the passive detectors used. It should be noted that during some periods not all detectors were available in all positions whilst in many cases two Makrofol detectors were exposed in parallel, allowing a check of the reproducibility of this detector material. Doubtful results are indicated by a question mark. The table is arranged according to neutron energies in ascending order. Results in the table for typical spectral conditions at CERN are surrounded by a thick line. Ideally the sum of the recorded neutron and gamma doses should be equal to the dose measured by the monitor. However, considerable discrepancies between the figures are noticed in some cases when comparing the results of the passive detectors with the integrated dose of the monitors. In some cases dose rates were low and monitor readings were near to background so that the intercalibration with the Cerberus became difficult. In other cases, the monitor position was not directly accessible during accelerator operation. In such cases the 'calibration factor' was determined by an intelligent guess with a strong bias towards the safe side.

In position 36 the monitor is placed near a cable duct where low-energy neutrons stream out accompanied by a considerable gamma component. Both Makrofol and the NTA film give low readings, whilst the CR39 with its extended response covers the low- energy part of the spectrum much better.

Monitor 61 is placed inside and near the exit of the labyrinth leading to the Antiproton Collector (ACOL) target cave, i.e. not a typical position. The ionization chamber not only sees the degraded neutrons from the beam interaction in the production target but is also immersed in a cloud of radioactive air containing positron emitters, i.e. ${ }^{15} \mathrm{O},{ }^{13} \mathrm{~N}$ and ${ }^{11} \mathrm{C}$. Consequently the positrons annihilate in the 
iron wall of the detector, resulting in a high reading. A beta dose of $2.5 \mathrm{mSv}$ was recorded on the gamma film, confirming the presence of positrons.

The situation at position 532 is one which is generally avoided in a shielding configuration around a high-energy accelerator. If an iron shield is not covered by at least $80 \mathrm{~cm}$ of concrete, low-energy neutrons will dominate the stray field. In such a case the CR39 detector is clearly preferred to the NTA film.

In the case of the neutrons streaming backwards in the Linac tunnel the monitor 23 is not accessible during operation hence its reading possibly greatly overestimates the dose. Again for low-energy neutrons, as expected, CR39 gives a higher reading than the NTA film.

In position 1443, neutrons are measured in the lateral direction from a small beam loss point. The doses accumulated on the passive detectors are too low to permit a good intercomparison.

In case of a secondary beam lost on a block of depleted uranium (monitor 1584) a neutron energy distribution similar to a fission spectrum is expected. Adding the doses recorded on the NTA film or CR39 to the gamma dose results in a total dose that agrees favourably with the value recorded by the monitor. The same is true for positions 13 and 21 . In all three cases, with spectra still on the low-energy side but of a kind that could be encountered in experimental areas of CERN, the doses recorded by Makrofol are lower than that of CR39 and the NTA film.

The following points belong to the more typical hard accelerator spectra. In such an environment all three track detectors give reasonable results when intercompared. Also monitor 62 is placed inside the shielding enclosure and apparently overestimates the dose considerably. In view of high dose rates on the PS shielding bridge (monitor 43), this place is not accessible during accelerator operation but is a favorable position to expose dosemeters. In this case, the limited measuring range of the NTA emulsion is noticed. The specific number of tracks per dose equivalent in a spectrum where high-energy particles dominate is about a factor of three higher than for the calibration with ${ }^{238} \mathrm{Pu}-\mathrm{Be}$ neutrons. Owing to the great number of tracks recorded, the films exposed during periods IV and V could only be counted with great difficulty whilst the film of period II marked by an asterisk could not be evaluated at all.

A few dosemeters were sent to the LBL Berkeley to be exposed in the radiation environment around the HILAC. The results show a tendency towards a relative underestimate of CR39 compared with the detectors having a higher threshold. The track distribution scanned on the NTA emulsion revealed indeed a rather hard neutron spectrum. However, the values recorded are too small to explain with certitude whether the decrease in sensitivity of CR39 has to be attributed to the high neutron energies involved. 
The exposures near the unshielded kaon beam (monitor 1442) and in the beam of muons behind an end-stop (monitor 65) are of a rather exotic nature. In the case of muons dominating the radiation field, the discrepancy between the monitor reading and the result of the gamma film is of a particular interest. This is partly explainable by the density effect that charged relativistic particles undergo when passing through a solid material. The specific ionization is reduced in a solid owing to the polarization of the medium when compared with the same material in gaseous form ${ }^{(14)}$.

\section{CONCLUSIONS AND FUTURE OUTLOOK}

The long-term study of nuclear track detectors has shown that all three of those tested are suitable for personal neutron monitoring in the stray field around highenergy particle accelerators. This is a considerable improvement on the situation during the last intercomparison ${ }^{(3)}$. However, still none of the detectors can be considered as a personal dosemeter, in view of the broad neutron energy range that has to be covered in an accelerator environment. In practice, this basic drawback poses no problem as owing to the low dose rates generally encountered at CERN personal 'doses' of greater than $1 \mathrm{mSv}$ recorded in a wearing period are extremely rare (about five per year). As a rule, all these cases are followed up by an investigation into the circumstances of the exposure conditions. As a result, corrections of the individual dose are rather frequent.

With respect to energy response a preference should be given to CR39 as this detector provides a signal even for small doses received in low-energy neutron fields. Polucarbonate showed a slightly higher energy threshold than the NTA film during the experiments. The resulting smaller response could be corrected by choosing a more conservative conversion factor for Makrofol. For the nuclear emulsion the possibility of a fading cannot be excluded in spite of all the precautions taken. On the other hand, the plastic detectors can suffer from spurious signals caused by the presence of radon as had been experienced in the case of Makrofol. An effective protection against this contamination is particularly important should detectors be worn for periods of several months.

For the choice of the method the cost factor is important in cases where as at CERN, more than 4000 persons are periodically monitored for neutron exposures. A rough estimate suggests that the replacement of the NTA film by Makrofol would increase the annual expenditure of $100 \mathrm{kSfr}$ by a factor of two whilst the switchover to CR39 would result in a factor of about four.

Finally, it should be mentioned that with the present state of individual monitoring one has to face the possibility that the quality factor for neutrons will increase from 10 to 20 in the energy range from 0.1 to $2 \mathrm{MeV}$ as proposed by ICRP(15). Of the presently available detectors, CR39 will have good characteristics with respect to 
energy response in order to meet the challenge. However, the other important parameter that must be reviewed critically in the new situation is the lower limit of detection of the detector employed.

\section{ACKNOWLEDGEMENT}

The author would like to thank Drs. D. Bartlett of NRPB and E. Piesch of KfK Karlsruhe not only for supplying the CR39 and Makrofol detectors, respectively, but also for their constructive criticism and useful advice. Many technicians of CERN's Radioprotection Group helped in the exposure of the detectors and analysing the results of the monitor readings. 


\section{REFERENCES}

1. Bartlett, D.T. and Creasy, F.L., Latent image fading in nuclear emulsions, Phys. Med. Biol. 22, 736 (1977).

2. Höfert, M., Status and future outlook of personal neutron monitoring around particle accelerators, Paper presented at the 2nd Conference on Radiation Protection and Dosimetry, Orlando (1988), CERN TIS-RP/217/CF.

3. Höfert, M., Bartlett, D.T. and Piesch, E., Personnel neutron monitoring around high energy accelerators, Radiat. Prot. Dosim. 20, 103 (1988).

4. Höfert, M., Personal neutron monitoring in an accelerator environment, Paper presented at the $22^{\text {nd }}$ International Symposium on Radiation Physics, Gaussig (1990), CERN TIS/90-03/CF.

5. Bartlett, D.T., Steele, J.D. and Stubberfield, D.R., Development of a single element neutron dosemeter for thermal, epithermal and fast neutrons, Nuclear Tracks, 12, 645, (1986).

6. Gilvin, P.J., Bartlett, D.T. and Steele J.D., The NRPB PADC Neutron Personal Dosimetry Service, Radiat. Prot. Dosim. 20, 99 (1988).

7. Al Najjar, S., Piesch, E. and Jozefowicz, K., The two-step electrochemical etching technique applied for polycarbonate track etched detectors, 15th Int. Conf. Particle Tracks in Solids, Marburg, (1990), to be published in Nuclear Tracks.

8. Höfert, M., Two years of practical experience with the LR115 as hadron detector, Nuclear Tracks 8, 317 (1983).

9. Swanson, W.P. and Thomas, R.H., Dosimetry for radiological protection at highenergy particle accelerators, Lawrence Berkeley Lab. Report LBL-242119 Rev. (1989), to be published as a chapter in: The Dosimetry of Ionizing Radiation, Vol.3, Academic Press, New York.

10. Luszik-Bhadra, M., Alberts, W.G. and Piesch, E., Neutron energy response and background of electrochemical etched nuclear track detectors: study of various CR39 materials, Radiat. Prot. Dosim. 32, 99, (1990).

11. Piesch, E. Ed., Neutron irradiations of proton-sensitive track etch detectors: Results of the Joint European/USA/Canadian Irradiations, EURADOS-CENDOS Report 1987-01, KfK 4305 (1987).

12. Höfert, M., The NTA emulsion: An ill-reputed but misjudged neutron detector, In Proc. 10th DOE Workshop on Personnel Neutron Dosimetry, Acapulco 1983, In CONF-8308/40-PNL-SA-12352, p. 107 (Battelle Northwest, Washington) (1984). 
13. Höfert, M. and Stevenson, G.R., Dose equivalent measurements around GeV accelerators, Radiat. Prot. Dosim. 9, 235, (1984).

14. Höfert, M., Dosemeter response to muons, Radiat. Prot. Dosim. 20, 149, (1987).

15. ICRP Publication 60, in the press, (1991). 


\begin{tabular}{|c|c|c|c|c|c|c|c|c|c|}
\hline Detector & & NTA & & & CR39 & & & Makrofo & \\
\hline Period & I & II & III & I & II & IIII & I & II & III \\
\hline Boclamend & 0.1 & 0.3 & 0 & 0 & 0 & 0 & 0 & 0 & ?1.6 \\
\hline Dackgivulle & 0 & 0 & 0 & 0 & 0 & 0.2 & 0 & 0 & ?1.4 \\
\hline Cf, $1 \mathrm{mSv}$ & 0.8 & & 0.8 & 1.7 & 1.1 & & 0.7 & & ?1.7 \\
\hline & 0.9 & & 1.0 & 1.7 & 1.4 & & 0.8 & & $? 2.0$ \\
\hline $\begin{array}{l}\mathrm{Pu}-\mathrm{Be}, \\
1 \mathrm{mSy} \text { in }\end{array}$ & 0.9 & 0.8 & 1.0 & 1.2 & 0.9 & 1.6 & 1.4 & $1.1 \pm 0.1$ & $? 2.6$ \\
\hline free air & 1.0 & 1.0 & 0.9 & 1.3 & 0.9 & 1.4 & 1.2 & $1.0 \pm 0.2$ & $? 1.7$ \\
\hline & & & & & & & & $0.9 \pm 0.1$ & \\
\hline $\mathrm{Pu}-\mathrm{Be}$ & 2.1 & & 1.9 & 2.3 & 1.6 & 2.7 & 2.5 & $1.9 \pm 0.1$ & \\
\hline free air & 1.8 & & 2.1 & 2.2 & ?5.3 & 2.7 & 2.4 & $1.7 \pm 0.1$ & \\
\hline & & & & & & & & $2.0 \pm 0.2$ & \\
\hline $\begin{array}{l}\mathrm{Pu}-\mathrm{Be}, \\
2 \mathrm{mSv} \text { on }\end{array}$ & 1.9 & 1.8 & & 2.3 & 1.8 & & 1.8 & & \\
\hline phantom & 2.0 & 1.8 & & 2.2 & 2.1 & & 2.4 & & \\
\hline
\end{tabular}

Table 1: Result of calibration checks performed at CERN for the detectors used in the intercomparison for irradiation periods I to III. All values are given in $\mathrm{mSv}$. Doubtful results are indicated by a question mark. 


\begin{tabular}{|c|c|c|c|c|c|c|c|c|}
\hline $\begin{array}{l}\text { Moni- } \\
\text { tor }\end{array}$ & Period & $\begin{array}{l}\text { Position or } \\
\text { field }\end{array}$ & $\begin{array}{c}\mathrm{H} \\
\text { Mon. }\end{array}$ & $\begin{array}{c}\mathrm{H} \\
\text { gamma }\end{array}$ & $\begin{array}{l}\text { NTA } \\
\text { film }\end{array}$ & CR39 & $\begin{array}{c}\text { Makrofol } \\
1\end{array}$ & $\begin{array}{c}\text { Makrofol } \\
2\end{array}$ \\
\hline 36 & $\begin{array}{l}\text { I } \\
\text { II } \\
\text { IV } \\
\text { V }\end{array}$ & $\begin{array}{l}\text { Cable duct } \\
\text { at the } \\
\text { Booster }\end{array}$ & $\begin{array}{r}30.7 \\
24.3 \\
1.5 \\
3.7\end{array}$ & $\begin{array}{l}6.3 \\
6.9 \\
0.4 \\
0.9\end{array}$ & $\begin{array}{l}1.7 \\
1.1 \\
0.4 \\
0.4\end{array}$ & $\begin{array}{l}6.0 \\
4.4 \\
0.3 \\
2.4\end{array}$ & $\begin{array}{l}0.5 \\
1.0 \\
2.9 ?\end{array}$ & $\begin{array}{l}0.9 \\
0.9\end{array}$ \\
\hline 61 & $\bar{I}$ & ACOL 1 & 11.8 & 1.0 & 2.4 & 4.8 & 2.7 & 2.6 \\
\hline 532 & II & iron shield & 14.9 & 8.9 & 5.8 & 10.2 & & \\
\hline$\overline{23}$ & $\begin{array}{l}\text { I } \\
\text { II } \\
\text { IV } \\
\text { V }\end{array}$ & $\begin{array}{l}\text { back- } \\
\text { streaming } \\
\text { neutrons } \\
\text { in Linac }\end{array}$ & $\begin{array}{r}16.3 \\
25.9 \\
2.0 \\
3.1\end{array}$ & $\begin{array}{l}1.4 \\
2.5 \\
0.2 \\
0.4\end{array}$ & $\begin{array}{l}1.3 \\
2.6 \\
0.4 \\
0.5\end{array}$ & $\begin{array}{l}4.4 \\
3.6 \\
0.8 \\
0.8\end{array}$ & $\begin{array}{l}0.3 \\
1.1 \\
2.5 ? \\
2.2 ?\end{array}$ & $\begin{array}{l}1.0 \\
1.1 \\
2.8 ?\end{array}$ \\
\hline 1443 & $\begin{array}{l}\text { II } \\
\text { III }\end{array}$ & $\begin{array}{l}\text { neutrons } \\
\text { from side }\end{array}$ & $\begin{array}{l}7.7 \\
4.1\end{array}$ & $\begin{array}{l}1.7 \\
0.9\end{array}$ & $\begin{array}{l}0.4 \\
0.2\end{array}$ & $\begin{array}{l}0.3 \\
1.5\end{array}$ & $\begin{array}{l}0.3 \\
0.7\end{array}$ & 0.3 \\
\hline 1584 & II & Uranium & 10.8 & 3.4 & 6.9 & 7.8 & 2.9 & 2.3 \\
\hline 13 & $\begin{array}{l}\text { I } \\
\text { II }\end{array}$ & $\begin{array}{l}\text { Chicane } \\
\text { near TT } 1\end{array}$ & $\begin{array}{l}6.9 \\
2.1\end{array}$ & $\begin{array}{l}1.1 \\
0.8\end{array}$ & $\begin{array}{l}4.7 \\
2.7\end{array}$ & $\begin{array}{l}4.6 \\
2.1\end{array}$ & $\begin{array}{l}2.9 \\
2.0\end{array}$ & $\begin{array}{l}2.3 \\
1.6\end{array}$ \\
\hline 21 & $\begin{array}{l}\text { I } \\
\text { II }\end{array}$ & Linac & $\begin{array}{l}5.0 \\
7.0\end{array}$ & $\begin{array}{l}1.3 \\
2.6\end{array}$ & $\begin{array}{l}2.7 \\
4.0\end{array}$ & $\begin{array}{l}2.2 \\
2.3\end{array}$ & $\overline{1.0}$ & 1.0 \\
\hline 62 & I & ACOL 2 & 12.2 & 1.8 & 2.5 & 3.3 & 2.8 & 3.2 \\
\hline 42 & $\begin{array}{l}\text { I } \\
\text { II }\end{array}$ & $\begin{array}{l}\text { PS North } \\
\text { hall }\end{array}$ & $\begin{array}{l}1.6 \\
5.5\end{array}$ & $\begin{array}{l}0.9 \\
0.7\end{array}$ & $\begin{array}{l}0.4 \\
2.2\end{array}$ & $\begin{array}{l}0.6 \\
1.8\end{array}$ & $<0.1$ & 0.3 \\
\hline 772 & II & West hall & 3.5 & 1.2 & 1.8 & 0.9 & & \\
\hline 54 & II & PS South & 2.6 & 0.7 & 2.2 & 0.8 & 0.9 & 1.2 \\
\hline 43 & $\begin{array}{l}\text { I } \\
\text { II } \\
\text { IV } \\
\text { V }\end{array}$ & $\begin{array}{l}\text { PS } \\
\text { shielding } \\
\text { bridge }\end{array}$ & $\begin{array}{c}9.6 \\
109.3 \\
3.7 \\
3.6\end{array}$ & $\begin{array}{l}0.9 \\
7.3 \\
0.3 \\
0.3\end{array}$ & $\begin{aligned} & 5.3 \\
& * \\
\sim & 8 \\
\sim & 7\end{aligned}$ & $\begin{array}{r}7.3 \\
57.8 \\
4.8 \\
5.6\end{array}$ & $\begin{array}{r}6.2 \\
68.3 \\
5.2 \\
5.6\end{array}$ & $\begin{array}{r}6.1 \\
65.9 \\
4.0 \\
4.1\end{array}$ \\
\hline$\overline{\mathrm{LBL}}$ & VI & $\begin{array}{l}\text { HILAC } \\
\text { Berkeley }\end{array}$ & $\begin{array}{l}1 \\
\sim 2 \\
\sim 2\end{array}$ & $\begin{array}{l}0.0 \\
0.0 \\
0.2\end{array}$ & $\begin{array}{l}1.0 \\
1.1 \\
1.0\end{array}$ & $\begin{array}{l}0.6 \\
0.9 \\
1.1\end{array}$ & $\begin{array}{l}1.0 \\
1.3 \\
1.6\end{array}$ & \\
\hline 128 & I & Site Monit. & 0.2 & 0.2 & $<0.1$ & $<0.1$ & $<0.1$ & 0.2 \\
\hline 1522 & $\begin{array}{l}\text { II } \\
\text { III }\end{array}$ & $\begin{array}{l}\text { SPS North } \\
\text { experi- }\end{array}$ & $\begin{array}{l}0.9 \\
1.4\end{array}$ & $\begin{array}{l}0.7 \\
0.4\end{array}$ & $\begin{array}{l}0.3 \\
0.0\end{array}$ & $\begin{array}{l}0.3 \\
0.6\end{array}$ & $\begin{array}{r}<0.2 \\
0.8\end{array}$ & $<0.2$ \\
\hline 1462 & $\begin{array}{l}\text { II } \\
\text { III }\end{array}$ & $\begin{array}{l}\text { mental } \\
\text { hall }\end{array}$ & $\begin{array}{l}3.9 \\
2.8\end{array}$ & $\begin{array}{l}1.9 \\
1.1\end{array}$ & $\begin{array}{l}1.2 \\
0.5\end{array}$ & $\begin{array}{l}0.7 \\
0.8\end{array}$ & $\begin{array}{l}0.4 \\
1.0\end{array}$ & 0.3 \\
\hline 1442 & $\begin{array}{l}\text { II } \\
\text { III }\end{array}$ & $\begin{array}{l}\text { K beam no } \\
\text { shielding }\end{array}$ & $\begin{array}{l}4.2 \\
3.0\end{array}$ & $\begin{array}{l}2.1 \\
1.1\end{array}$ & $\begin{array}{l}0.8 \\
1.0\end{array}$ & $\begin{array}{l}0.6 \\
2.0\end{array}$ & $\begin{array}{l}0.3 \\
1.2\end{array}$ & $\begin{array}{r}0.4 \\
<0.1\end{array}$ \\
\hline 65 & $\bar{I}$ & muons & 93.8 & 18.8 & 2.1 & 5.9 & 2.8 & 4.2 \\
\hline
\end{tabular}

Table 2: Results of intercomparisons made in the vicinity of fixed installed monitors. For an explanation see the text under results and discussion. A neutron film that could not be evaluated because of the great number of tracks is indicated by an asterisk. Doubtful results are indicated by a question mark. 
Figure 1: Detector response with respect to dose equivalent as a function of energy: NTA is the neutron film, CR39 material made by Pershore Moulding as available from NRPB(6), MF stands for Makrofol (polycarbonate) as provided by KfK Karlsruhe ${ }^{(7)}$ etched in two steps either chemically (EC) and electrochemically (ECE) or both steps electrochemically (ECE+ECE). The latter process was used in this study whilst the former etching technique had been used in a previous intercomparison ${ }^{(3)}$. 
Response in $\mathrm{mSv}^{-1} \mathrm{~cm}^{-2}$ (for NTA in $\mathrm{mSv}^{-1} \mathrm{~mm}^{-2}$ )

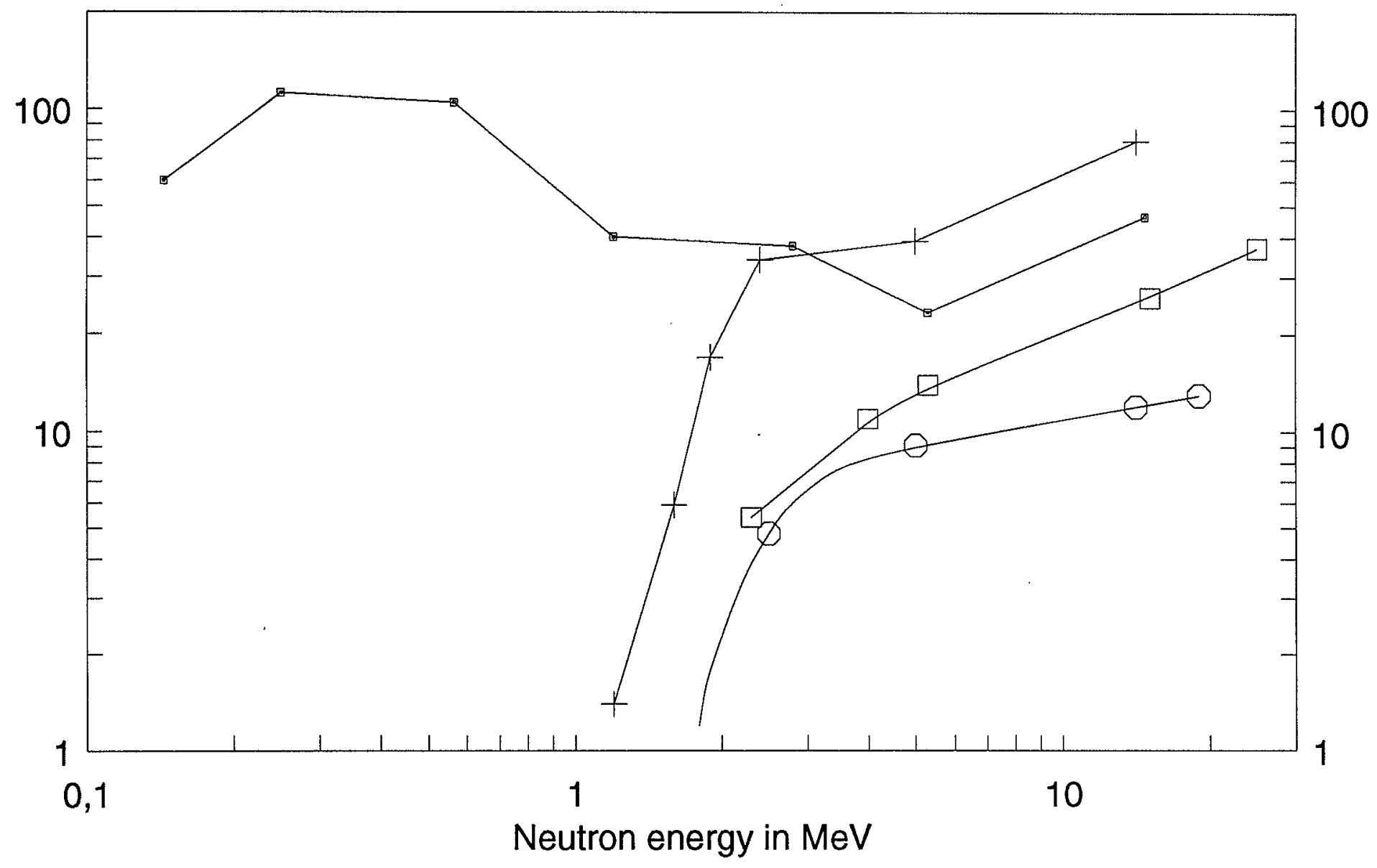

$\square$ NTA $\rightarrow$ CR $39 \quad$ MF (CE+ECE) $\quad$ MF $(E C E+E C E)$ 